\title{
Development of a knowledge management system for complex domains
}

\author{
André Perott ${ }^{\mathrm{a}^{*}}$, Nils Schader ${ }^{\mathrm{a}}$, Ralph Bruder ${ }^{\mathrm{a}}$ and Jörg Leonhardt ${ }^{\mathrm{b}}$ \\ ${ }^{a}$ University of Technology, Institute of Ergonomics, Petersenstraße 30, 64287 Darmstadt, Germany \\ ${ }^{\mathrm{b}}$ DFS Deutsche Flugsicherung GmbH, Am DFS-Campus 10, 63225 Langen, Germany
}

\begin{abstract}
Deutsche Flugsicherung GmbH, the German Air Navigation Service Provider, follows a systematic approach, called HERA, for investigating incidents. The HERA analysis shows a distinctive occurrence of incidents in German air traffic control in which the visual perception of information plays a key role. The reasons can be partially traced back to workstation design, where basic ergonomic rules and principles are not sufficiently followed by the designers in some cases. In cooperation with the Institute of Ergonomics in Darmstadt the DFS investigated possible approaches that may support designers to implement ergonomic systems. None of the currently available tools were found to be able to meet the identified user requirements holistically. Therefore it was suggested to develop an enhanced software tool called Design Process Guide. The name Design Process Guide indicates that this tool exceeds the classic functions of currently available Knowledge Management Systems. It offers "design element" based access, shows processual and content related topics, and shows the implications of certain design decisions. Furthermore, it serves as documentation, detailing why a designer made to a decision under a particular set of conditions.
\end{abstract}

Keywords: Knowledge Management Systems, Ergonomics, Design Process, Air Traffic Control

\section{Introduction}

DFS Deutsche Flugsicherung GmbH (DFS), the German Air Navigation Service Provider, has the objective to ensure the safe, orderly, and expeditious flow of air traffic above Germany [1]. In a world with a continuously growing number of aircraft movements, air traffic control (ATC) is under pressure to increase its performance without sacrificing the high level of safety. Almost all organizations with a high degree of complexity and interaction, socalled High Reliability Organizations (HRO), are confronted with similar challenges.

Some of the most significant factors influencing the goal achievement of HROs arise from the complexity inside the system. Complexity, from a Human Factors and Ergonomic perspective, is determined by the number of equipment subsystems, the manner with which these interact, and what is required of the system operator [2]. Complexity and the high degree of interaction make HROs vulnerable to all kinds of errors, more precisely system errors and human errors, which may peril the compliance of the current high safety standards.

To manage and control these risks, DFS established an extensive technique to analyze safety relevant incidents: HERA (The Human Error in Air Traffic Management Technique). If a work system and its complexity are analyzed in a structured manner, errors may be anticipated and avoided.

\section{State of the art}

\subsection{Results and Implications of HERA}

The theory of Resilience Engineering describes the Air Traffic Management (ATM) systems as complex and interactive, wherein a cause-effect quotation of incidents is no longer sufficient. Erik Hollnagel stated that

\footnotetext{
* Corresponding author. Email: perott@iad.tu-darmstadt.de
} 
“... untoward events more often are due to an unfortunate combination of a number of conditions, than to the failure of a single function or component" [3].

HERA at DFS is used under these theoretical principles: Human Error is a symptom, not a cause, and the combination of the components of a system leads to undesirable outcomes. HERA uses a systematic approach to enable investigators to find explanations for incidents in the overall context of the ATM system. "Incident" in this context, means the loss of the required separation between two or more aircraft. HERA is a pan-European proposition in order to collect enough information for creating a useful database, since incidents are fortunately rare.

However there are trends toward changing this definition: DFS is in a process to replace the term $\mathrm{Hu}$ man Error by Decision Point. This re-labeling helps to shift the blame and causation away from the operator. The theory behind is that failure and success have the same source: A Decision Point. Only the result determines the decision to be an error or a success [4]. For a more thorough description of the HERA method and the underlying theoretical background, see $[5,6,7]$.

Figure 1 and 2 provide an evaluation of HERA incident reports from 2005 to 2009. When looking at the totals in the different Error Detail categories, two major accumulations can be identified: Perception \& Vigilance and Planning \& Decision-making. While the totals are decreasing over the years, their relative shares remain high $-27.7 \%$ and $52.9 \%$ respectively in 2009 (see figure 1).

Figure 2 depicts the corresponding accumulated numbers of Error Mechanisms. By far the most frequent mechanism is "No detection of visual information". This means that some malfunction occurred in the controller's visual perception of the presented information. Though this may be due to several different causes ranging from distraction to expectation bias, DFS had a strong suspicion at the time that ergonomic issues of the utilized equipment were the cause.

Among other things this suspicion was supported by an analysis of incidents from the Swedish airspace between 1988 and 1998 with the HERA technique. Very similarly to the German cases, $21 \%$ of the identified failures fell within the domain of "Perception \& Vigilance". Even more striking is the fact that "workplace design and HMI" was the predominant group of Contextual Conditions [8]. Furthermore there are continuous international intentions to fur- ther integrate Human Factors in ATM for very similar reasons. A recent development is NASA's and FAA's goal to better coordinate their human factors research efforts "to achieve the intended benefits of investments in NextGen" [9]. Also Eurocontrol highlights the importance of the "HF contributions to the ATM performance targets, current strengths and weaknesses" [10].

For further investigation of the HERA findings, workstations and HMI were evaluated by the Institute of Ergonomics in Darmstadt. As expected, some weaknesses could be detected, even in newly acquired or designed systems. HMI displays, which are the main mode of visual information presentation, suffered from issues concerning font sizes and types, viewing distance problems, overlapping information etc. While most of these could be resolved, the question still arose of how and why design flaws continue appearing despite the manifold expertise of DFS' equipment designers and engineers.

\subsection{Current Design Context within the DFS}

As discussed above the HERA-Analysis indicates that system design and errors are related. However, HERA provides no indication of how to ergonomically improve current systems in order to reduce errors. HERA follows the premise that Human Errors appear during the operation but in fact the origin may lead back to the very early stages of system design.

In retrospect it is hard to understand why a designer chose an inappropriate design option and how the design process needs to be modified for minimizing the risk of Human Errors in future systems. However, this information is essential to define areas for improvement regarding the overall workstation design process.

The Institute of Ergonomics identified three areas for improvement during their investigations which are knowledge acquisition, knowledge application, and knowledge transfer. These three areas for improvement are mainly a result of organizational aspects and the focus on non-ergonomic competencies in DFS human resources.

\subsection{Current Knowledge Management Concepts}

In cooperation with the Institute of Ergonomics in Darmstadt the DFS investigated possible approaches that may support designers in achieving better ergonomic systems. As discussed above, knowledge acquisition, knowledge application, and knowledge 
transfer were identified as most critical factors inside the DFS. All these factors are simultaneously addressed by a Knowledge Management System [11, 12] which is therefore a promising possibility.

Roland Maier defines a Knowledge Management System (KMS) as

"an ICT (Information and Communication Technology) system in the sense of an application system or an ICT platform that combines and integrates functions for the contextualized handling of both, explicit and tacit knowledge, throughout the organization or that part of the organization that is targeted by a Knowledge Management initiative" [13].

Maier also defines the typical task of a KMS, which is the support of

"networks of knowledge workers in the creation, construction, identification, capturing, acquisition, selection, valuation, organization, linking, structuring, formalization, visualization, distribution, retention, maintenance, refinement, evolution, accesing, search and last but not least the application of knowledge" [13].

KMS concepts are generally application-oriented and/or technology driven. This makes it difficult to give an all-embracing overview of all existing KMS concepts. However the literature describes general modules of KMSs which different applications share. Table 1 gives an example of different KMS modules structured by different authors. Franz Lehner classifies KMSs with reference to their functionality [12], while Norbert Gronau uses their practical application as a differentiating factor [14]. Jens Hartmann on the other hand differs by means of the underlying data [15]. Roland Maier's classification in turn is based on market studies [13]. This study suggests consolidating these views and distinguishes four general KMS modules:

- Content Management Systems

- Artificial Intelligence Systems

- Project Management Systems

- Groupware Systems

Content Management Systems include all systems that digitally represent information. They can be further differentiated into Document Management Systems (e.g. PDF-Database) and advanced Content Management Systems (includes structured information including information for the information layout, e.g. Intranet).

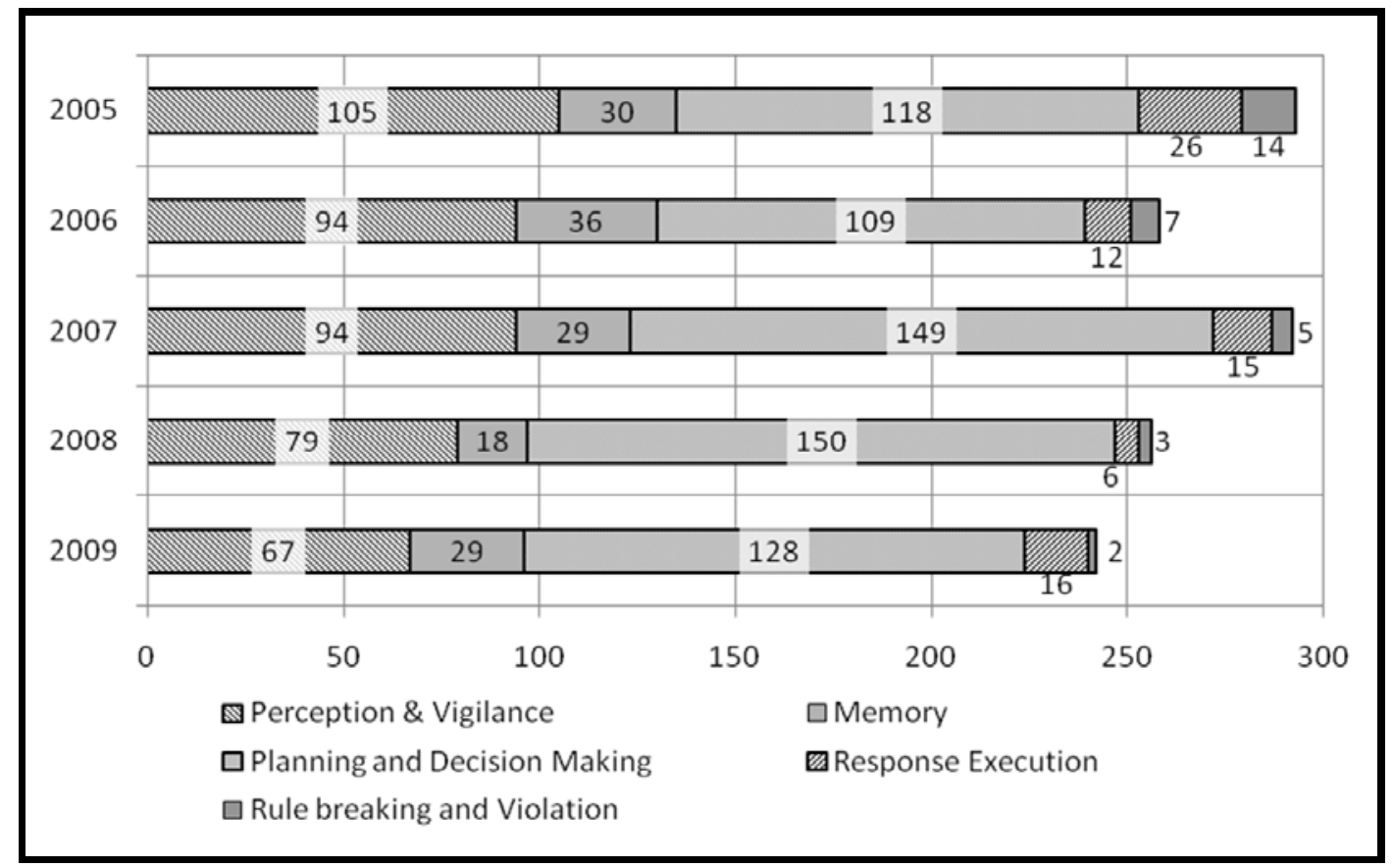

Fig. 1 - Error Types of total annual HERA incident reports during 2005-2009 


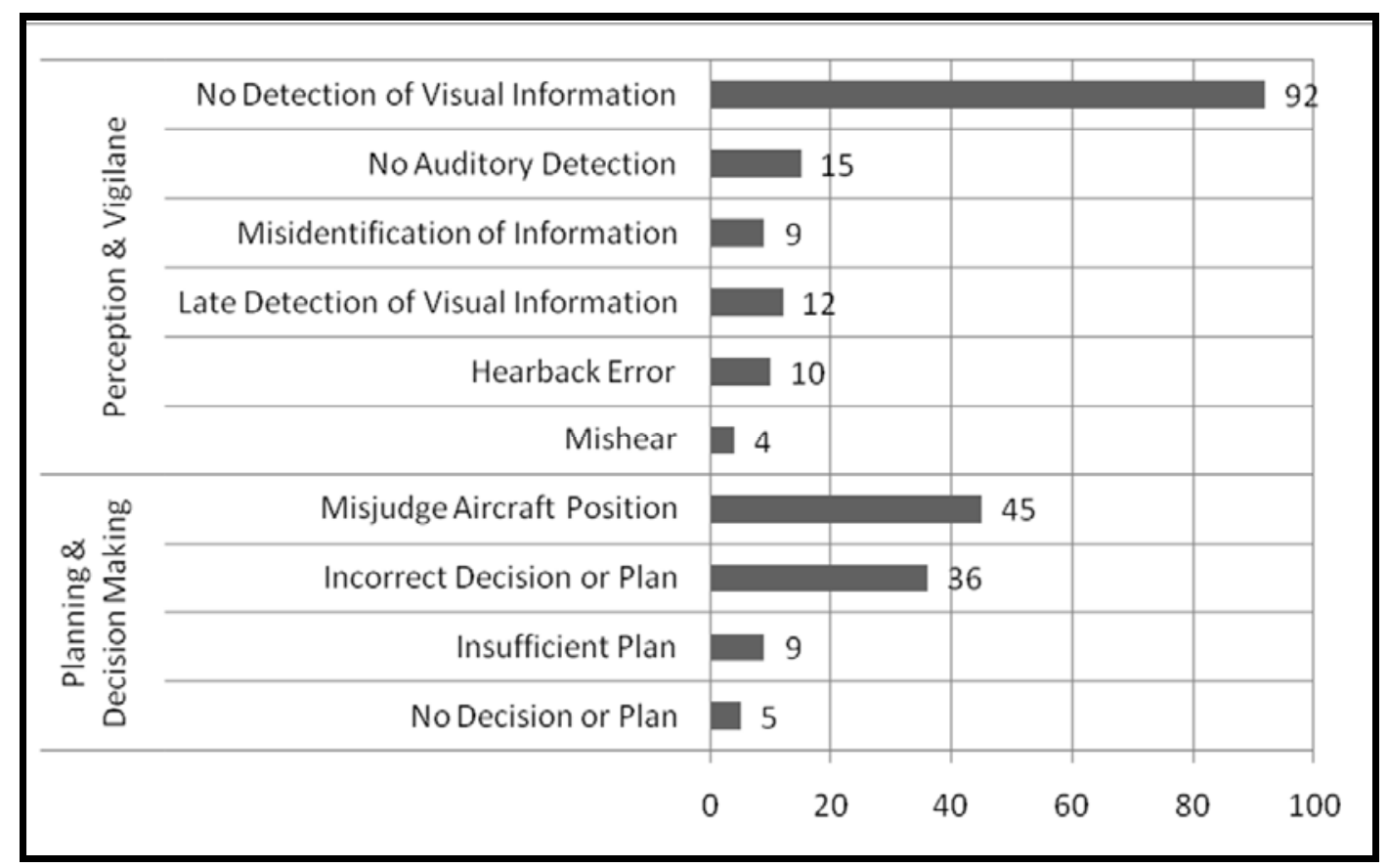

Fig. 2 - Accumulated numbers of Error Mechanisms (EM) for incidents in upper German airspace during 2005-2009

Table 1

Literature review of KMS systematizations

\begin{tabular}{|c|c|c|}
\hline Author & Classification by & Modules of KMSs \\
\hline Franz Lehner & functionality & $\begin{array}{l}\text { Groupware / Social Software } \\
\text { Content Management Systems } \\
\text { Artificial Intelligence Systems } \\
\text { Executive Information System } \\
\text { Other Systems }\end{array}$ \\
\hline Norbert Gronau & practical application & $\begin{array}{l}\text { Social Software } \\
\text { Document Management Systems } \\
\text { Content Management Systems } \\
\text { Portal Software } \\
\text { E-Learning Systems } \\
\text { Integrated KMSs }\end{array}$ \\
\hline Jens Hartmann & underlying data & $\begin{array}{l}\text { Data oriented systems } \\
\text { Content oriented systems } \\
\text { Knowledge oriented systems } \\
\text { Process oriented systems } \\
\text { Group oriented systems } \\
\text { Other Systems }\end{array}$ \\
\hline Roland Maier & products on market & $\begin{array}{l}\text { Knowledge Repositories } \\
\text { Knowledge Discovery and Mapping } \\
\text { E-learning Suites } \\
\text { Community Builder } \\
\text { Meta-Search Systems } \\
\text { Enterprise Knowledge Portals } \\
\text { Push-Oriented Systems } \\
\text { Collaboration } \\
\text { Visualization and Navigation Systems }\end{array}$ \\
\hline
\end{tabular}


Artificial Intelligence Systems provide support in a problem solving situation by applying rules and facts in between different information sets. This may include learning components. Examples are Expert Systems, Agent Systems, or Configuration Systems.

Project Management Systems provide formal and standardized workflows that should be considered. In general they help to administer, accomplish, or control a process.

Groupware Systems provide an infrastructure to communicate (e.g. email), collaborate (e.g. googledocs) and to coordinate (e.g. scheduler) inside an organization.

Intrinsically a KMS should integrate all four modules. In practice KMS concepts balance these modules differently, depending on the underlying knowledge management strategy, available technologies, and the actual knowledge-base. Therefore, further studies were conducted in the DFS to derive specific KMS requirements and to clarify how far current KMS Technologies match these requirements.

\section{Methodology}

To identify the knowledge requirements and needs this study applied the user-centered design process according to ISO 9241-202 [16]. It is intended for use by those responsible for planning, designing, developing, acquiring, and evaluating information and/or ICT equipment and services. Part of this approach is the context of use specification, which includes an analysis of the final user, related user tasks, current tools as well as the physical and organizational environment. The context of use specification then leads to the definition of requirements in the next phase.

To specify the context of use and related requirements, a qualitative, explorative study was conducted over a period of more than two years. The base population of this study is quite small $(\mathrm{N} \leq 30)$ due to the number of workstation designers inside the DFS. Fortunately, almost all relevant workstation designers were available and participated in at least one workshop or scenario.

All in all, six workshops were conducted, each with eight to fifteen participants. Alongside workshops, this study used the scenario technique as an additional method to understand current approaches and ergonomic problems of the designers. Here "Scenarios" are stories that can describe the fictitious use of fictitious KMSs by a fictitious user $[17,18]$. Scenarios are very powerful, especially in a complex context, as they give meaningful insight as to how new or modified KMS may be used and how current approaches may be improved.

Therefore workstation designers were asked to describe informal ergonomic issues with which they were challenged. Each real ergonomic subproblem was then transformed to a problem-scenario and a use-scenario, which was discussed with the project owners afterward. The use-scenario described characteristics of a fictive tool that could help in solving the problem. An important incentive for the participants was their expectation that reported ergonomic sub problems were actually solved during the scenario process and that they could use the results in practice. For detailed information on how scenarios were used during this study refer to [19].

\section{Results \& Discussion}

As discussed above, four general KMS module types can be distinguished. These are Content Management Systems, Artificial Intelligence Systems, Project Management Systems, and Groupware Systems. A holistic KMS concept should consider each module. The following section presents the DFS requirements for each module, which were derived from the context of use.

\subsection{Requirements for the Content Management module}

Designers in the DFS are interested in finding a reliable source for ergonomic information. Many different sources such as standards, guidelines, books, journals, and reports are available, as aviation is one of the most discussed topics in Human Factors. For a non-ergonomist it seems impossible to find an overview of the field. Therefore a good starting point is to provide a collection of relevant ergonomic literature, studies, and past projects.

However, a pure Document Management System doesn't provide any contextual information. The designer still needs to evaluate which information is essential and which can be neglected in some cases. Another problem occurs when two reliable sources offer conflicting information and designers need to prioritize the results. Deadline pressure does not allow for an intensive analysis of available documents and their relevance.

Once the designers have collected the relevant documents, they need to transfer this information to 
their specific context. There are multiple unique ATC characteristics that need to be taken into account for this purpose. The question at hand for a typical designer is: Is this specific ergonomic information approved for usage in the ATC context? FAA's Human Factors Design Standard offers ergonomic guidelines particularly for usage in air traffic control [20]. Although the document is public domain, very comprehensive and specific, designers rarely use it. One reason is that guidelines often do not reflect the actual design context [21].

Advanced Content Management Systems (like Wikis) allow the placement several documents in an overall context and the discussion of their implications. To give an example, users could add a new article (e.g. display design), post relevant documents, discuss a current project, and share their know-how. HROs however have to assure the highest safety standards. Therefore the information should be reliable, evaluated, and approved before being presented to the designers. For this reason an editorial staff consisting of ergonomic experts is essential for content maintenance. In addition to running text there must be clear formalized ergonomic requirements available, including a basic prioritization (must, shall, should). Related to these requirements are specific design decisions that can be made by the designer and which should be represented by the KMS.

\subsection{Requirements for the Artificial Intelligence module}

There are many dependencies in the ATC context that should be considered before design decisions can be made. For instance, if a designer selects daylight as a modality for lighting, ergonomic studies suggest using a positive display polarity (black text on white background). Designers have difficulties predicting future ergonomic implications of today's decision. The available ergonomic literature gives some indicators, but they are scattered and not systematized. These dependencies between design decisions should be represented by a basal artificial intelligence in the KMS. Interested employees and project successors are then able to understand conflicting requirements and the reasoning behind a decision or modification in ergonomic design.

Designers usually think in design elements: They have a specific task to fulfill (e.g. designing a HMI) and strive for this goal, step by step. There is a risk that they may ignore other related ergonomic design issues. For example, the font height inside a HMI is determined by the viewing distance between the operator and the display. This again is constrained by the operators working position (leaned forward, upright or relaxed position) and this in turn is related to the defined controllers' task. All these factors which impact the font height are not just a matter of HMI design. Therefore the designers need a holistic approach which includes these relations. If a designer is working on a specific design element, the system should automatically suggest related design elements and provide additional information on how they are related and what needs to be done to comply with the relation.

\subsection{Requirements for the Project Management module}

The context of use analysis resulted in three different stakeholder groups for the KMS, which should be considered: The Editors use the tool to manage ergonomic knowledge regarding workstation design. They should be able to write articles, define requirements, priorities information, define new constrains, suggest methods or approaches, structure the content, and build new relations between different knowledge elements. The Project Manager should be able to model workflows and processes within the KMS. He or she gives the project a basic shape by defining the order in which design elements should be treated. For this purpose the Project Manager needs adequate assistance from an ergonomic perspective. For example it is highly recommended to design the basic control room layout, communication channels, etc. before designing one concrete controller working position.

Once the Project Manager has modeled a design workflow, the relevant ergonomic knowledge should be automatically assigned to the particular project steps. The Project Collaborators, which are the persons responsible for one or more steps defined by the Project Manager, should then see the related sub steps of the process and directly access the relevant knowledge. Moreover they should be able to decide on specific requirements (e.g. how large the font size on a computer screen is in the actual project). These decisions should be documented and visible to the Project Leader. Furthermore the Project Leader should be able to request a report about the status of the project. 


\subsection{Requirements for the Groupware module}

The DFS designers work closely together and the DFS already established a well organized infrastructure for communication and collaboration. Therefore it is not necessary to implement additional communication services within an ergonomic KMS. However designers are often unsure of which ergonomic aspects are worth coordinating with internal experts. They are not aware of potential conflicts. Therefore the KMS should indicate which questions should be coordinated in any case.

A particular design project may last for more than ten years. Therefore it is not unusual that the project staff changes over this period. Even though there is a formal handover process, a lot of information remains with the predecessors. Once the predecessors leave the company, all of their personal implicit knowledge is lost for the whole organization. In hindsight, it is often impossible for the successors to comprehend why specific decisions were made and which circumstances led to this decision. This is the case, when the need for coordination is recognized, but the contact person is not longer available for various reasons. Therefore design decisions should be documented, especially if the designer chooses to differ from a standard ergonomic proposal. Project collaborators should therefore be able to understand the reasoning behind a modification in ergonomic requirements.

\subsection{Currently available frameworks for KMSs}

A market study showed that there is no framework available that integrate all requirements described above. Available tools only address partial aspects but fail to integrate the mentioned functions holistically.

Wikis are perfectly suited for implicit knowledge sharing and collaboration [22]. However they clearly lack formalism, which makes automated data processing difficult. They are not suitable for structured data, systemized ergonomic requirements, and tracing project decisions.

Customization tools, configurators, or variant management tools in contrast allow the formal representation of relations. It is possible to define typical components and their relation to one another (e.g. the screen polarity is part of HMI design. If you choose a positive polarity, you must also choose daylight during the control room design). However there are information types that cannot be formalized in a way that can be automatically interpreted by the KMS. Qualitative requirements (e.g. that the experience of the controller must be considered for HMI- color coding) and designers experience are some examples. A HRO-KMS should offer both: On the one hand, the KMS must be flexible enough to allow the storage of implicit knowledge; on the other hand it should offer a stringent formalism where appropriate.

Project management systems typically include planning, scheduling, budget, quality, and documentation tools. Their task is to coordinate business units, ensure a high level of process transparency and to provide advice on the manner and order in which tasks should be completed to achieve an overall business objective [23]. However they are also rigid and only intended for frequently repeated business incidents and not for complex and creative design processes. Furthermore these tools are typically not linked to a knowledge base and therefore don't suggest a process or sequence for ergonomic design. But this was identified as a essential feature for achieving better ergonomic systems.

\section{Implications \& Conclusion}

As discussed above, none of the currently available knowledge frameworks suit the derived requirements. The DFS decided to develop a new KMS, called Design Process Guide. The Design Process Guide will be integrated company-wide and ideally be managed by a central editorial unit with ergonomic expertise inside the DFS.

The intention is to reduce the current necessity of a personal private network, to build a reliable knowledge base, and to document ergonomic decisions during a project. As a result, designers also have a central contact for ergonomic questions and direct access to ergonomic expertise whenever information inside the Design Process Guide is insufficient. The presented knowledge can then be modified or expanded, being further tailored to an application in air traffic control.

The name Design Process Guide indicates that this tool exceeds the classic functions of an ergonomic content management system. It offers a "design element" based access, shows processual and content related topics, and deduces implications of certain design decisions. Furthermore, it serves as documentation, detailing why a designer made a decision under a particular set of conditions. All the content and 
relations are entered and administrated by ergonomic experts. This may take time and effort, but ensures reliable and ATC focused information in the long term. Figure 3 shows early design drafts of the Design Process Guide.
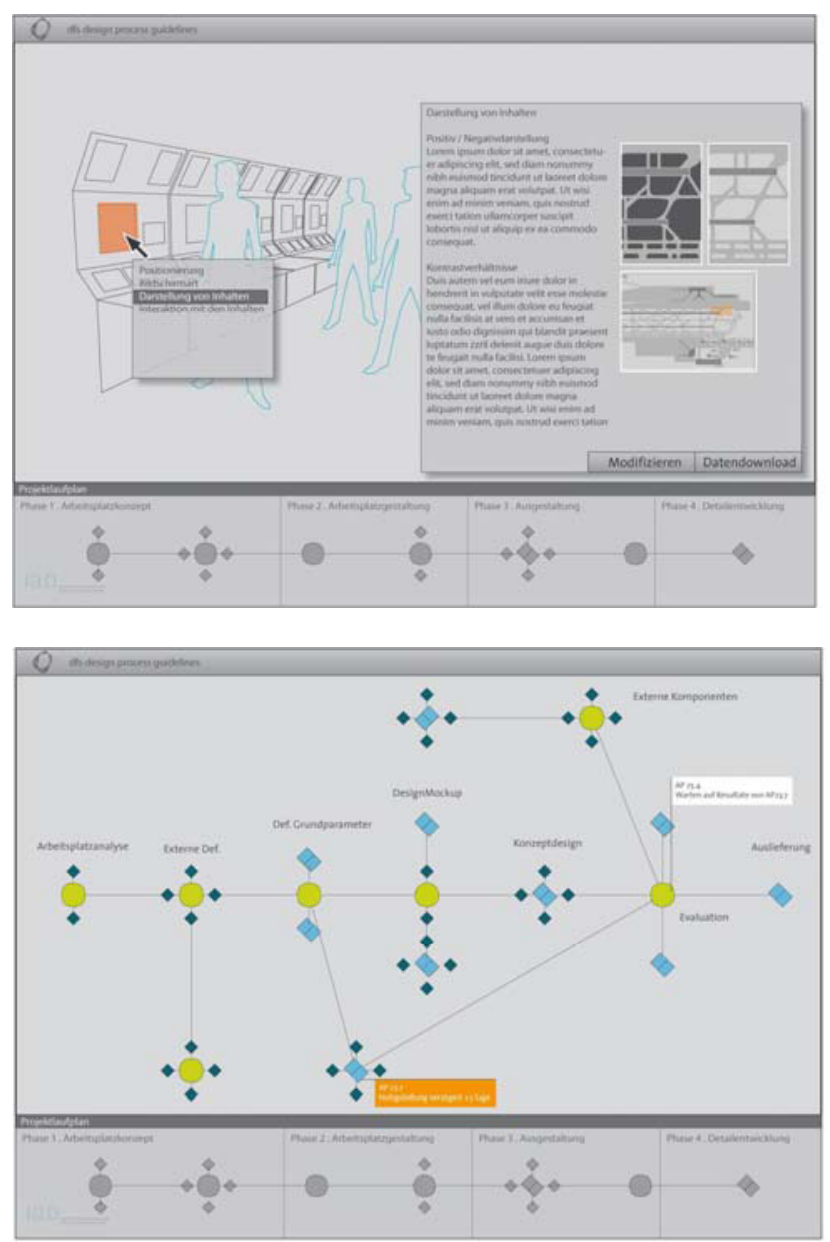

Fig. 3 - Design Process Guide design studies

\section{References}

[1] Deutsches Luftverkehrsgesetz (LuftVG), Bundesministerium der Justiz (Ed.), 2010

[2] D. Meister, The History of Human Factors and Ergonomics, CRC, London, 1999

[3] E. Hollnagel, D. D. Woods, N. Leveson: Resilience Engineering - Concepts and Precepts, Ashgate Publishing, London, 2006

[4] E. Hollnagel, The ETTO Principle: Why things that go right sometimes go wrong, Ashgate Publishing, London, 2009

[5] EUROCONTROL, Technical Review of Human Performance Models and Taxonomies of Human Error in ATM (HERA), http://www.eurocontrol.int/humanfactors/public/standard_pag e/hera.html, Accessed 21 th August 2011

[6] EUROCONTROL, The Human Error in ATM Technique (HERA-JANUS,

http://www.eurocontrol.int/humanfactors/public/standard_pag e/hera.html, Accessed 21 th August 2011

[7] EUROCONTROL, A Method for Predicting Human Error in ATM (HERA-PREDICT),

http://www.eurocontrol.int/humanfactors/public/standard_pag e/hera.html, Accessed 21 th August 2011

[8] Reason, J.: Human error. Cambridge University Press, New York, 1990

[9] Joint Planning and Development Office, Federal Aviation Administration and National Aeronautics and Space Administration, Next Generation Air Transportation System - Human Factors Research Coordination Plan, http://www.jpdo.gov/newsArticle.asp?id=151, Accessed 21th August 2011

[10]EUROCONTROL, HP in the Single European Sky ATM Research Programme (SESAR), http://www.eurocontrol.int/humanfactors/public/standard_pag e/HP in SESAR.html, Accessed 21th August 2011

[11] G. Probst, S. Raub, K. Romhardt, Wissen managen - Wie Unternehmen ihre wertvollste Ressource optimal nutzen, 6th ed., Wiesbaden, Gabler/GWV, 2010

[12]F. Lehner, Wissensmanagement - Grundlagen, Methoden und technische Unterstu tzung, 2nd ed., München/Wien, Hanser, 2008

[13]R. Maier, Knowledge Management Systems: Information and Communication Technologies for Knowledge Management, 2nd ed., Springer, Berlin/Heidelberg, 2004

[14]N. Gronau, Anwendungen und Systeme für das Wissensmanagement: ein aktueller Überblick, 3rd ed., Gito, Berlin, 2009

[15] J. Hartmann, Ontologiebasierte Gestaltung und Umsetzung von Wissensmanagementsystemen, Ph.D. Dissertation, University of Karlsruhe, 2007

[16]ISO 9241-210, Ergonomics of human-system interaction - Part 210: Human-centred design for interactive systems, Beuth, Berlin, 2010

[17]J. M. Carroll, Szenario-Based Design - Envisioning Work and Technology in System Development. John Wiley \& Sons, New York, 1995

[18] M. B. Rosson, J. M. Carroll, Usability Engineering - Szenario-Based Development of Human-Computer-Interaction, Morgan Kaufmann Publishers, San Francisco, 2002

[19]A. Perott, R. Helbig, R. Bruder, J. Leonhardt, Ermittlung von Benutzeranforderungen bei komplexen Systemen mit Hilfe von Szenarien, in: Bericht zum 57. Kongress der Gesellschaft für Arbeitswissenschaft, GFA-Press, Dortmund, 2011, pp. 215-218

[20]FAA 2003, The Human Factors Design Standard (HFDS). http://hf.tc.faa.gov/hfds/ (2003). Accessed 21th August 2011

[21] H. Kim, Effective organization of design guidelines reflecting designer's design strategies, in: Int. J. of Ind. Ergonomics, Vol. 40, Nr. 6, pp. 669-688

[22]H. Yang and C. Lai, Understanding knowledge-sharing behavior in Wikipedia, in: Behaviour \& Information Technology, Vol. 30, No.1, Taylor and Francis, 2011, pp. 131-142

[23]P. Dadam, M. Reichert, S. Rinderle-Ma, Prozessmanagementsysteme, in: Informatik Spektrum, Bd. 64, Nr. 4, Springer, 2011, pp. 364-376 